\title{
Thermal behavior and chromatographic characterization of oil extracted from the nut of the Butia (Butia capitata)
}

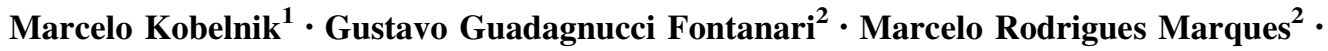 \\ Clóvis Augusto Ribeiro ${ }^{3} \cdot$ Marisa Spirandeli Crespi ${ }^{3}$
}

Received: 14 March 2015/Accepted: 6 January 2016/Published online: 12 February 2016

(C) Akadémiai Kiadó, Budapest, Hungary 2016

\begin{abstract}
The Butia capitata (Arecaceae family) is a palm that can reach approximately from 3 feet up to 5 feet tall and is commonly found in southern Brazil. This palm produces bunches of fruit with a diameter of about $2 \mathrm{~cm}$ which has an acid taste and is enjoyed by many people and also wild animals such as rodents and birds. The aim of this study was to extract the oil present in butia nuts and evaluate its composition and thermal behavior. The oil was characterized by chromatography and its thermal behavior by thermogravimetry (TG) in nitrogen and oxygen atmospheres under different heating rates. The chromatographic profile of this oil reveals a predominance of saturated fatty acids. The analysis performed by thermogravimetry indicates that under oxygen atmosphere, this oil showed mass gain before the onset temperature of thermal decomposition. In nitrogen, only one mass loss was observed. The kinetic behavior showed the relationship between the uses of two sample masses, indicating the same kinetic behavior under oxygen analysis.
\end{abstract}

Keywords Thermal behavior - Butia nut oil Chromatographic analysis

Marcelo Kobelnik

mkobelnik@gmail.com

Gustavo Guadagnucci Fontanari

gufontanari@gmail.com

1 Centro Universitário do Norte Paulista, UNORP, São José do Rio Preto, SP, Brazil

2 Faculdade de Saúde Pública da Universidade de São Paulo (FSP/USP), São Paulo, Brazil

3 Departamento de Química Analítica, Instituto de Química, Unesp - Univ. Estadual Paulista, C.P. 355, 14800-900 Araraquara, SP, Brazil

\section{Introduction}

The Butia eriospatha species is known as butia in the south of Brazil. It has a dioecious species canopy measuring around four meters high and 1 meter in diameter, which blooms in spring and summer in the southern region of Brazil [1]. There is also a kind of butia widespread in regions of the Brazilian savanna popularly known as " $\mathrm{co}$ quinho azedo" [2]. However, both differ only in terms of its stem size and diameter, the period of flowering and fruit ripening. The species found in southern Brazil, after maturation, has a yellow color and acid flavor similar to that found in the Brazilian savannah regions. Its fruit is edible, but is not used industrially because of the short flowering time and also the non-uniform distribution of these palms in the region [3]. Furthermore, this fruit also plays an important role in the ecosystem as it is consumed by different species of rodents and birds and also has potential for use as food. The butia also has a nut that has a high fat content that has not yet been explored. In addition, the studies of oils from several fruit from Brazil are very important in view of the different possibilities of finding new oils compositions. Thus, each studied oil may contribute to several industrial purposes such as paints and varnishes or more appropriately use in fragrances, aromas, flavors, etc. Besides, the butia suffers from the absence of natural regeneration due to the use of the fields for agriculture. Therefore, study on the butia can draw attention to the commercial use of this fruit and thus ensure the cultivation in Brazilian fields.

The aim of this work was the extraction of lipids present in this nut, to characterize their fatty acid profile by gas chromatography and also perform the thermal study by thermogravimetry (TG) in oxygen and nitrogen gas purge. Thus, the obtained results of the present study improve the 
knowledge on this oil including its crystallization behavior and also the kinetic behavior which was carried out on two samples masses in nitrogen and oxygen gas purge, in order to determine the effect of these changes on obtained results.

\section{Experimental}

\section{Materials}

The butia nuts (Butia eriospatha) were obtained from Ponta Grossa City, Paraná State, Brazil. Mature fruits were collected during the December month, the period of maturation, cooled and subsequently submitted to a manual pulp removal process. The seeds were separated, dried at room temperature to provide maneuverability condition to remove the nut. The nuts were removed manually by breaking the seeds. Colloquially, this is known as brown coconut in virtue of possessing the same characteristics as a coconut. The nuts were ground in a domestic blender, homogenized, and sieved $(0.42-\mathrm{mm}$ mesh), resulting in butia nut flour. The butia nut oil was obtained with $n$ hexane (analytical reagent), in an extraction bath at ambient temperature. The $n$-hexane phases were removed and concentrated in a rotary evaporator.

\section{Methods}

\section{Lipid profile}

Fatty acid profiles of the oils extracted from the flours were determined using the method of Folch et al. [4], followed by lipid methylation to produce fatty acid methyl esters according to Hartman and Lago [5]. The fatty acid determination was carried out on GC-2010 Gas Chromatograph Shimadzu, Tokyo, Japan, fitted with a SP2560 fused silica column $\quad(100 \mathrm{~m} \times 0.25 \mathrm{~mm} \quad$ I.D., $\quad$ film thickness $\times 0.20 \mu \mathrm{m}$ by Supelco). The oven temperature was programmed to rise from 100 to $235{ }^{\circ} \mathrm{C}$ at the rate of $10{ }^{\circ} \mathrm{C} \mathrm{min}{ }^{-1}$ under the following conditions: carrier gas $\mathrm{H}_{2}$ $\left(2.5 \mathrm{~mL} \mathrm{~min}^{-1}\right)$, split ratio 50:1, flame ionization detector (FID) $250{ }^{\circ} \mathrm{C}$. The peaks of fatty acids were identified by comparison with the retention time of a standard mixture of fatty acid methyl esters (37 FAME Mix 47885, Supelco).

The results were expressed as a percentage of the area of each peak over the total area of all fatty acids in the chromatogram.

\section{Thermal analysis}

TG/DTG curve measurements were taken using a SDT 2960, from TA Instruments, with sample masses of 5 and
$20 \mathrm{mg}$, both in $\alpha$-alumina crucible with heating rate of 5 , 10 , and $20{ }^{\circ} \mathrm{C} \mathrm{min}^{-1}$. Nitrogen and oxygen were used as purge gases to perform the TG curves with the flow rate of $100 \mathrm{~mL} \min ^{-1}$. The transition phase evaluation was performed by DSC evaluation. The measurements were taken using DSC1 Star ${ }^{\mathrm{e}}$ (Mettler Toledo) with a mass sample around $5 \mathrm{mg}$ in an aluminum crucible. The samples were cooled from 25 to $-80{ }^{\circ} \mathrm{C}$ and subsequently heated from $-80{ }^{\circ} \mathrm{C}$ up to $25^{\circ} \mathrm{C}$, both at cooling/heating rate of $1{ }^{\circ} \mathrm{C} \mathrm{min}{ }^{-1}$ under nitrogen as a purge gas at the flow rate of $50 \mathrm{~mL} \mathrm{~min}^{-1}$ atmosphere. Furthermore, in this paper the isoconversional method was adopted as a way of obtaining reliable and consistent kinetic information because it avoids the use of explicit kinetic models as mentioned in previous works [6-10]. Thus, in this work, the kinetic parameters were obtained using the approximation to the integral temperature based on the Jacobi fraction, as proposed by Capela and Ribeiro [11].

In addition, the ICTAC Kinetics Committee has recommended conditions to obtain kinetic data for thermoanalytical curves [12]. It is important to note that this Committee suggests three or more curves, because it has been considered that statistics require three minimal quantities of TG curves. Thus, this recommendation is followed in this paper because the uses of three curves are not a limiting condition for kinetic study. Moreover, this would not affect the work, but allows the discussion and preparation of new work by us and by other authors. We also consider it appropriate to use more than one sample mass and also purge gas in order to favor an interpretation of kinetic data as much as possible.

\section{Results and discussion}

The amount of oil extracted was about $41.7 \%$ by mass of the sample, and as visual characteristics at room temperature, this oil presented a liquid physical state with a characteristic smell similar to that of coconut oil. Next, the lipid profile of the oil was characterized and the results are shown in Table 1. It can be seen in Table 1 that this oil is predominantly composed of saturated fatty acids, representing almost $80 \%$ of its total composition, and therefore, the butia oil fatty acid profile is similar to other oils used for human consumption.

In addition, the stability and humectant properties make it useful for the industrial production of soaps, cosmetics, resins, and cleaning materials $[13,14]$. It has been suggested that the predominant fatty acid of this oil (lauric acid) also has antimicrobial activity and stimulates the immune system [15].

The TG/DTG curves under nitrogen purge gas are shown in Figs. 1 and 2. According to the DTG curves for 
Table 1 Fatty acid composition of butia nut oil

\begin{tabular}{lc}
\hline Fatty acid & Mean value ${ }^{\mathrm{a} / \%}$ \\
\hline Butyric (C4:0) & $4.3 \pm 0.7$ \\
Caprylic (C8:0) & $10 \pm 1.5$ \\
Capric (C10:0) & $11.3 \pm 0.6$ \\
Lauric (C12:0) & $38.8 \pm 0.3$ \\
Myristic (C14:0) & $7.5 \pm 0.2$ \\
Palmitic (C16:0) & $4.7 \pm 0.1$ \\
Stearic (C18:0) & $2.7 \pm 0.07$ \\
Oleic (C18:1 n9) & $16 \pm 0.4$ \\
Linoleic (C18:2 n6) & $3.4 \pm 0.1$ \\
Docosahexaenoic (C22:6 n3) & $1.1 \pm 0.1$ \\
\hline
\end{tabular}

${ }^{\mathrm{a}}$ Mean standard deviation

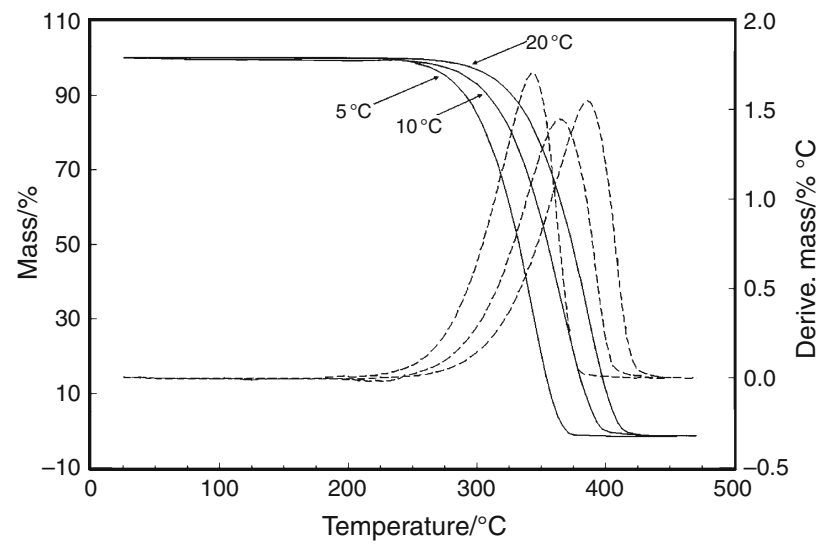

Fig. 1 TG/DTG curves of butia oil under nitrogen purge gas, with heating rates of 5,10 , and $20^{\circ} \mathrm{C} \mathrm{min}^{-1}$, sample mass of $5 \mathrm{mg}$ in $\alpha$ alumina crucible

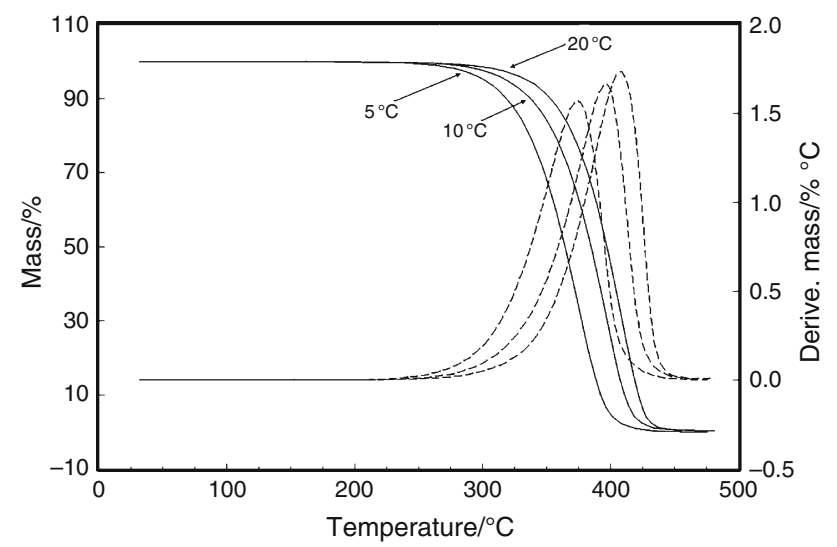

Fig. 2 TG/DTG curves of butia oil under nitrogen purge gas, with heating rates of 5,10 , and $20{ }^{\circ} \mathrm{C} \mathrm{min}-1$, sample mass of $20 \mathrm{mg}$ in $\alpha$ alumina crucible

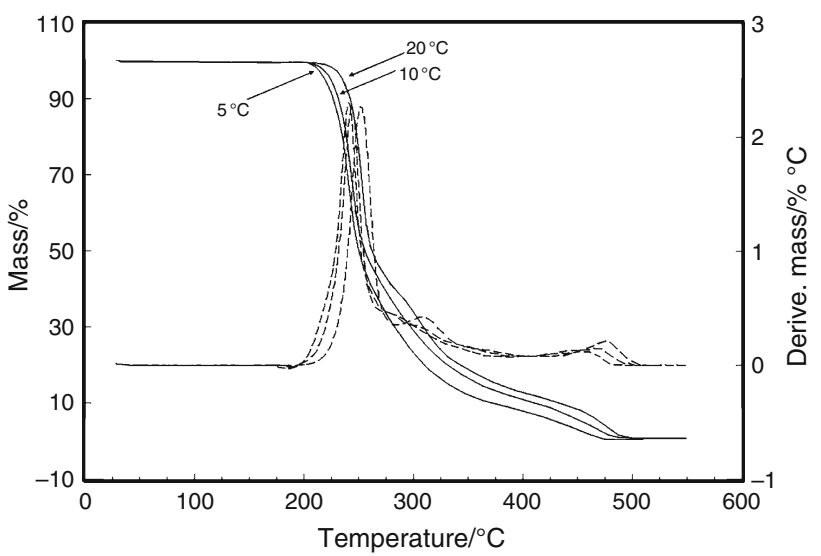

Fig. 3 TG/DTG curves of butia oil under oxygen purge gas, with heating rates of 5,10 , and $20{ }^{\circ} \mathrm{C} \mathrm{min}{ }^{-1}$, sample mass of $5 \mathrm{mg}$ in $\alpha$ alumina crucible

sample mass of $5 \mathrm{mg}$ (Fig. 1), the sample shows only one stage of thermal decomposition between 225 and $420{ }^{\circ} \mathrm{C}$. As can be seen, to the end of thermal decomposition, the presence of carbonaceous residues was not observed. Moreover, the analysis of sample mass of $20 \mathrm{mg}$ is shown in Fig. 2. The result shows that the behavior of 5 and $20 \mathrm{mg}$ sample masses does not change the profiles curves, because the character of thermal decomposition remains similar, as it considered only the one mass loss. However, the behavior during decomposition showed differences, considering that there is a large amount of mass, which of course has a higher molecular interaction. Thus, it is possible to see by DTG that the interval of thermal decomposition is between 250 and $450{ }^{\circ} \mathrm{C}$, and therefore, the thermal behavior was not the same in the thermal properties as presented by the sample of $5 \mathrm{mg}$.

The evaluations under oxygen purge gas are shown in Figs. 3 and 4. The sample mass of $5 \mathrm{mg}$ (Fig. 3) shows that the first stage of thermal decomposition occurs between 200 and $275{ }^{\circ} \mathrm{C}$ with mass loss of $59.96 \%$. The second stage of thermal decomposition occurs between 275 and $400{ }^{\circ} \mathrm{C}$, with mass loss of $29.04 \%$, followed by the third stage of mass loss from 400 to $500{ }^{\circ} \mathrm{C}$, with a variation in the TG curve of $10.24 \%$. At the end of the analysis, a small amount of carbonized residue was seen.

Figure 4 shows the dependencies of the amount of mass of the oil under oxygen, and as shown in DTG curves, the behavior of the oil varied with the heating rate. For evaluation under $5{ }^{\circ} \mathrm{C}$, the mass losses occur in four stages, where it is possible to see that the first stage of thermal decomposition occurs between 193 and $295{ }^{\circ} \mathrm{C}$, with a loss of $60.36 \%$. The second mass loss occurs from 295 to $367{ }^{\circ} \mathrm{C}$ with a loss of $15.33 \%$, which is followed by a fourth and fifth thermal decomposition in the intervals of 


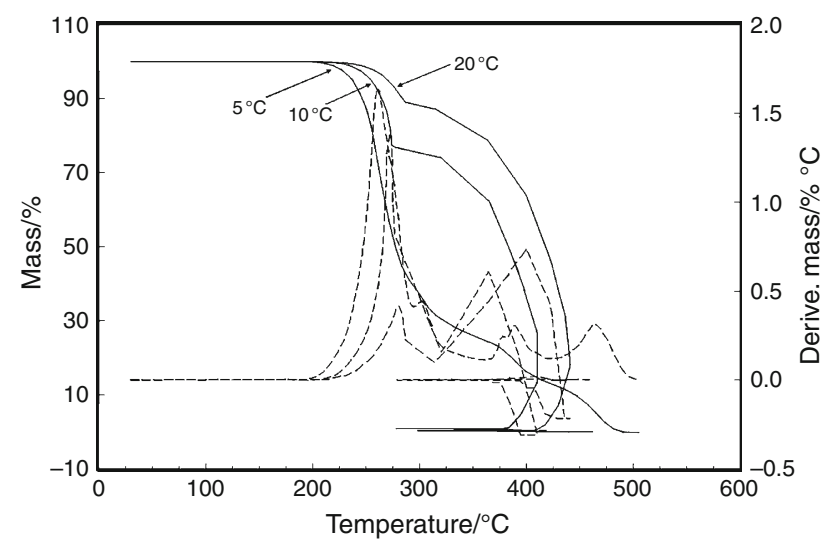

Fig. 4 TG/DTG curves of butia oil under oxygen purge gas, with heating rates of 5,10 , and $20{ }^{\circ} \mathrm{C} \mathrm{min}-1$, sample mass of $20 \mathrm{mg}$ in $\alpha$ alumina crucible

367-421 and $421-500{ }^{\circ} \mathrm{C}$, with 12 and $12.57 \%$ of mass losses, respectively. Now, TG results (Fig. 4) show that the oil under heating rates of 10 and $20{ }^{\circ} \mathrm{C} \mathrm{min}{ }^{-1}$ has several kinds of behavior, showing that the increase in speed of heating on the sample alters the behavior and the velocity of reaction. As shown in the DTG curve, the sample under $10{ }^{\circ} \mathrm{C}$ shows a thermal decomposition between 205 and $275^{\circ} \mathrm{C}$, with a loss of $22.69 \%$. After $275^{\circ} \mathrm{C}$, it is possible to observe that there is a stronger alteration in the TG/DTG curve, which was attributed to the effect of combustion. Also, it can be seen that the TG curve has a fall in temperature, of $410{ }^{\circ} \mathrm{C}$ down to $278^{\circ} \mathrm{C}$, which is the result of combustion of the sample. The analogous behavior can also be observed with a heating rate of $20{ }^{\circ} \mathrm{C} \mathrm{min}^{-1}$, where the interval of first thermal decomposition is between 212 and $288{ }^{\circ} \mathrm{C}$ with a loss of $10.96 \%$.

In addition, it is possible to observe that the analysis of the results obtained under oxygen purge gas shows the effect of interaction with the oil. Typically, the beginning of oxidation in edible vegetable oils is characterized by the absorption of oxygen through the fatty acid chain, which is generally identified by an increase in the initial mass of the sample. Apart from this, the amounts of unsaturated fat (around $20.5 \%$ ) in this oil make it especially prone to oxidation. In fact, TG curves of this oil with a sample mass of $5 \mathrm{mg}$, with heating rate of 5 and $10{ }^{\circ} \mathrm{C} \mathrm{min}{ }^{-1}$ (Fig. 5), show that they have an increase in mass. This same behavior has been seen in the sample mass of $20 \mathrm{mg}$. However, when using a heating rate of $20{ }^{\circ} \mathrm{C} \mathrm{min}{ }^{-1}$ no alteration was observed in the TG/DTG curves, which was attributed to the fast velocity of this condition of analysis. Thus, it is suggested that the increase in the heating rate does not allow oil oxidation.

Fatty acid behavior also depends on the crystallization stage, which can occur at several temperatures. This behavior has implications on industrial processing of

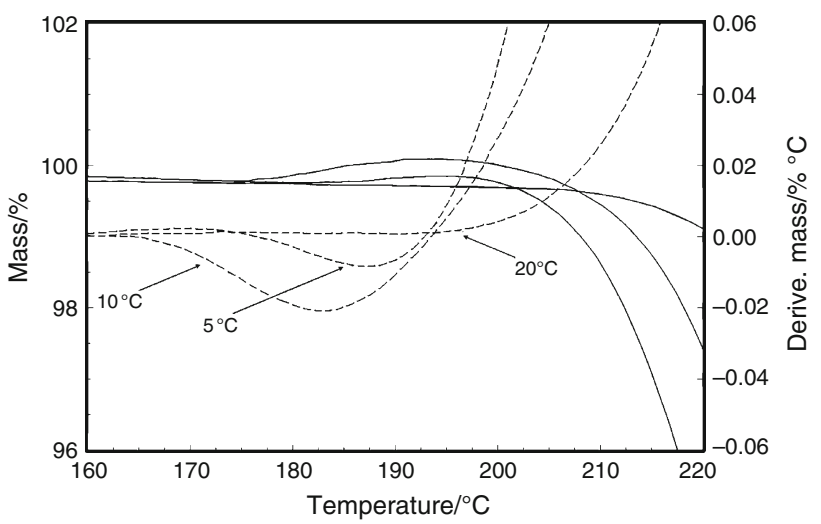

Fig. 5 TG/DTG curves of butia oil under oxygen purge gas, showing the oxidation stage with sample mass of $5 \mathrm{mg}$ in $\alpha$-alumina crucible

products than depend on the influence of plasticity, such as chocolates and margarines [16]. The samples were subjected to a cooling scan from $50{ }^{\circ} \mathrm{C}$ down to $-80{ }^{\circ} \mathrm{C}$, followed by a heating scan from that temperature up to $50{ }^{\circ} \mathrm{C}$. Both scans were performed at the rate of $1{ }^{\circ} \mathrm{C} \mathrm{min}-1$. Figure 6 shows these evaluations, where it is possible to see the typical DSC curves of butia oil with a sample mass of $5 \mathrm{mg}$. These curves were obtained during the cooling run from 50 to $-80{ }^{\circ} \mathrm{C}$, followed by a heating run from -80 to $50{ }^{\circ} \mathrm{C}$. For this sample, during the cooling, two thermal events were observed: (1) the first sharp exothermic peak, which was attributed to the crystallization of unsaturated fatty acids, and (2) a change in the base line, around $-30{ }^{\circ} \mathrm{C}$, which can be attributed to the transition phase in the sample. During the heating stage, it is possible to observe a broad endothermic event between -30 and $18{ }^{\circ} \mathrm{C}$. This event was attributed to a solid-liquid

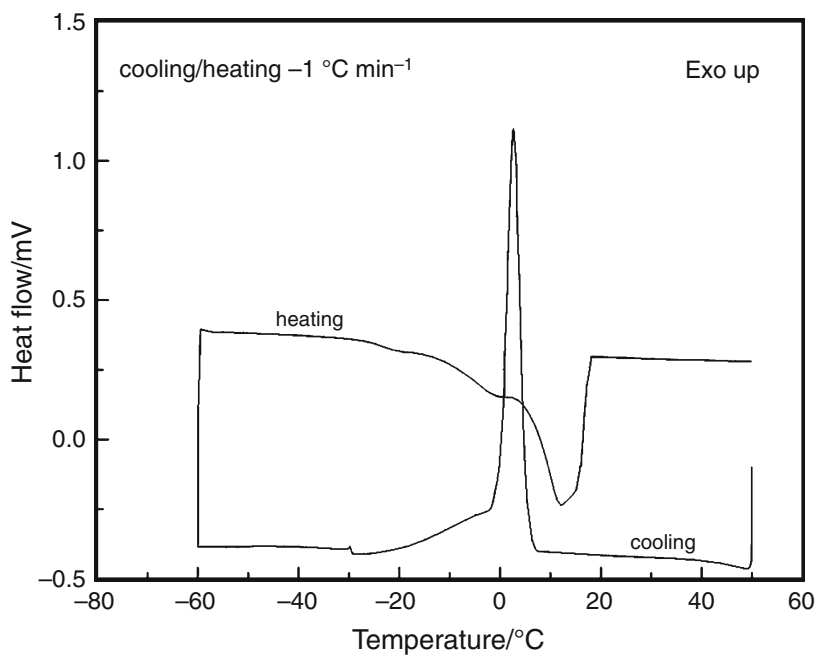

Fig. 6 DSC curves of butia oil under cooling and heating rate of $1{ }^{\circ} \mathrm{C} \mathrm{min}-1$, with sample mass of $5 \mathrm{mg}$ in aluminum crucible under nitrogen purge gas 
transition phase which takes place in reaction, due to the gradual increase in the temperature, indicating the significant changes in the physical properties of this oil. Thus, it is not possible to observe the absolute value of the melting point of this oil due to the large amount of fatty acid components. In general, the melting point in DSC curves exhibited sharp peaks. The absence of a sharp peak occurs because the process is based on the different melting points of the fatty acids in the mixture, which also depend on the chain length and their type of non-saturation (double bonds).

Table 2 provides the average of the activation energy and also the linear correlation obtained for two sample masses in oxygen and nitrogen purge gases. Based on the relation of the values obtained for the correlation coefficient $(r)$, the same indicates that the relationship between activation energy and conversion degree is satisfactory for the sample mass of $5 \mathrm{mg}$ under nitrogen, whereas for the other conditions there is a decrease in the linear fit attributed to the overlapping reactions.

As can be seen in Fig. 7 (nitrogen gas purge), the kinetic behavior is dependent on the mass utilized, when the sample mass of $5 \mathrm{mg}$ is smaller than that of $20 \mathrm{mg}$. Now, for analysis under oxygen purge gas (Fig. 8), the behaviors are similar to both samples. It is important to consider that the oils can behave differently during heating. For example, the oxidation of unsaturated fatty acids can produce a decrease in the thermal stability resulting in the formation of hydroperoxides and other products. The increase in viscosity and polymerization attributed to the various mixtures of saturated and unsaturated fatty acids are also determinant factors that need be considered in the process of degradation [17, 18]. Tan et al. [19] have also studied the stability of oils by isothermal condition and, according to the study carried out by them, the results indicate that the higher activation energy implies that the oil has a low stability to oxidation. In previous works, Kobelnik et al. have studied araça and bicuiba oils, both with several sample masses. When there is predominance of only a fatty acid, as occurs in the araça oil (linoleic acid (18:2 n6) $81.38 \%$ ), it is possible to observe that the behavior is similar to both masses under nitrogen and synthetic air

Table $2 E_{\mathrm{a}} / \mathrm{k} \mathrm{mol}^{-1}$ and correlation coefficient $(r)$ for first stage of thermal decomposition

\begin{tabular}{llll}
\hline Compound & Atmosphere & $E_{\mathrm{a}} / \mathrm{kJ} \mathrm{mol}^{-1 *}$ & $r^{*}$ \\
\hline Butia & $20 \mathrm{mg}$ (oxygen) & $189.45 \pm 0.12$ & 0.97166 \\
& $5 \mathrm{mg}$ (oxygen) & $177.16 \pm 0.11$ & 0.98297 \\
& $20 \mathrm{mg}$ (nitrogen) & $164.20 \pm 0.13$ & 0.98214 \\
& $5 \mathrm{mg}$ (nitrogen) & $104.94 \pm 0.07$ & 0.99496 \\
\hline
\end{tabular}

* Arithmetic mean

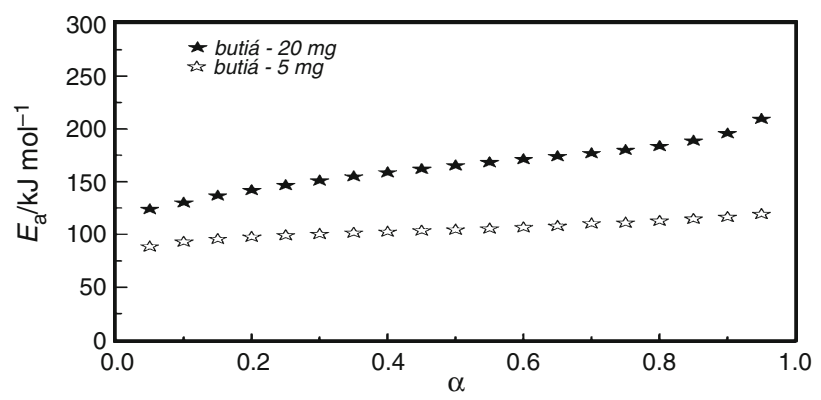

Fig. 7 Activation energy versus conversion degree under nitrogen purge gas

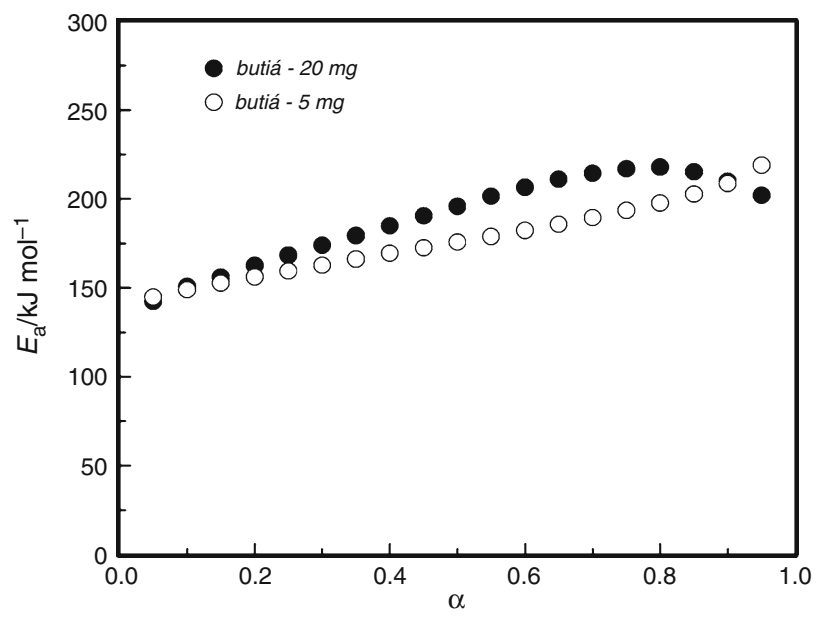

Fig. 8 Activation energy versus conversion degree under oxygen purge gas

purge gases. However, as shown in the bicuiba oil, which has a mixture of several saturated fatty acids with predominance of lauric $(34.7 \%)$ and myristic $(39.9 \%)$, the kinetic behavior shows this oil to provide several types of behavior under both gas purges utilized. The bicuiba oil shows that the activation energy under nitrogen gas purge with the sample mass of $20 \mathrm{mg}$ was smaller than that for $5 \mathrm{mg}$, but in oxygen gas purge the sample mass of $5 \mathrm{mg}$ has higher activation energy than for $20 \mathrm{mg}$. With regard to this work, with the analysis under oxygen condition, both sample masses have similar activation energy, while under nitrogen the $20 \mathrm{mg}$ has values greater than the mass of $5 \mathrm{mg}$. Thus, as occurred in the aforementioned works, in this paper it was possible to see that the activation energy is dependent on the composition of fatty acids. Finally, the oxidation implies several changes in activation energy due to the formation of several products during the heating, which, associated with minority fatty acids present in the sample, can lead to unexpected behavior. Therefore, the relationship between the activation energy and sample mass allows a better evaluation of the oils. 


\section{Conclusions}

The results of gas chromatographic analysis showed that this oil has a high amount of saturated fatty acids, which corresponds to around $80 \%$. The results of the TG and oxidant in an inert atmosphere and the use of different sample masses promote an understanding of the behavior of thermal oil. The TG also allows monitoring the profiles of TG curves under 5 and $10{ }^{\circ} \mathrm{C} \mathrm{min}^{-1}$ and shows the effect on the increasing mass of the oil, which is also associated with its chemical composition, because of the minor fatty acids that are present in the oil. It was also possible to observe that the use of a high-velocity heating rate $\left(20{ }^{\circ} \mathrm{C} \mathrm{min}^{-1}\right)$ maintains the integrity of the oil. As well as this, the combination of two sample masses and also two purge gases allows the evaluation of the results obtained for activation energy to be more convenient. Thus, in this work it was possible to verify that the reaction under oxygen is similar to both samples masses. The obtained result by DSC curve during the heating shows that an asymmetric event takes place and suggests the presence of several components with different melting points under the conditions used.

\section{References}

1. Dal Magro NG, Coelho SEM, Haida KS, Berté SD, Moraes SS. Comparação físico-química de frutos congelados de Butia eriospatha (Mart.) Becc. Do Paraná e Santa Catarina - Brasil. Revista Varia Scientia. 2006;06:33-42.

2. Lopes RM, Silva JP, Vieira RF, Silva DB, Gomes IS, AgostiniCosta TS. Composição de ácidos graxos em polpa de frutas nativas do cerrado. Rev Bras Frutic. 2012;34:635-40.

3. Fior CS, Rodrigues LR, Leionhardt C, Schwarz SF. Superação de dormência em sementes de Butia capitata. Ciência Rural. 2011;41:1150-3.

4. Folch J, Lees M, Sloane-Stanley G. A simple method for the isolation and purification of total lipids from animal tissues. J Biol Chem. 1957;226:497-509.

5. Hartman L, Lago RC. Rapid preparation of fatty acid methyl esters from lipids. Lab Pract. 1973;22(494):475-6.
6. Kobelnik M, Fontanari GG, Soares R, et al. Study of the thermal behavior of bicuiba oil (Virola bicuyba). J Therm Anal Calorim. 2014;115:2107-13.

7. Kobelnik M, Cassimiro DL, Dias DS, Ribeiro CA, Crespi MS. Thermal behavior of Jerivá oil (Syagrus romanzoffiana). J Therm Anal. 2011;106:711-5.

8. Souza JL, Kobelnik M, Ribeiro CA, Capela JMV. Kinetics study of crystallization of PHB in presence of hydroxy acids. J Therm Anal Calorim. 2009;97:525.

9. Kobelnik M, Cassimiro DL, Santos Dias D, Ribeiro CA, Crespi MS. Thermal behavior of araça oil (Psidium cattleianum Sabine). J Therm Anal Calorim. 2012;108:1281-6.

10. Kobelnik M, Fontanari GG, Cassimiro DL, Ribeiro CA, Crespi MS. Thermal behavior of coffee oil (Robusta and Arabica species). J Therm Anal Calorim. 2013;115:2045-52.

11. Capela JMV, Capela MV, Ribeiro CA. Nonisothermal kinetic parameters estimated using nonlinear regression. J Math Chem. 2009;45:769.

12. Vyazovkin S, Chrissafis K, Di Lorenzo ML, Koga N, Pijolat M, Roduitf B, Sbirrazzuoli N, Suñol JJ. ICTAC Kinetics Committee recommendations for collecting experimental thermal analysis data for kinetic computations. Therm Acta. 2014;590:1-23.

13. Medeiros EJL, Queiroga RCRE, Souza AG, Cordeiro AMTM, Medeiros AN, Souza DL, Madruga MS. Thermal and quality evaluation of vegetable oils used in ruminant feed. $J$ Therm Anal Calorim. 2013;112:1515-21.

14. Ezeh IE, Umoren AS, Essien EE. Udoh AP. Studies on the utilization of Hura crepitans L. seed oil in the preparation of alkyd resins. Ind Crops Prod. 2012;36:94-9.

15. Huang WC, Tsai TH, Chuang LT, Zouboulis CC, Tsai PJ. Antibacterial and anti-inflammatory properties of capric acid against propionibacterium acnes: a comparative study with lauric acid. J Dermatol Sci. 2014;73:232-40.

16. Ribeiro APB, Grimaldi R, Gioielli LA, Santos AO, Cardoso LP, Gonçalves LAG. Thermal behavior, microstructure, polymorphism, and crystallization properties of zero trans fats from soybean oil and fully hydrogenated soybean oil. Food Biophys. 2009;4:106-18.

17. Gouveia de Souza A, Oliveira Santos JC, Conceição MM, Dantas Silva MC, Prasad S. A thermoanalytic and kinetic study of sunflower oil. Braz J Chem Eng. 2004;21:265-73.

18. Vecchio S, Campanella L, Nuccilli A, Tomassetti M. Kinetic study of thermal breakdown of triglycerides contained in extravirgin olive oil. J Therm Anal Calorim. 2008;91:51-6.

19. Tan CP, Che Man YB, Selamat J, Yusoff MSA. Application of arrhenius kinetics to evaluate oxidative stability in vegetable oils by isothermal differential scanning calorimetry. JAOCS. 2001;78:1133-8. 